\title{
Correction to "Novel Anticoagulants in Atrial Fibrillation: A Primer for the Primary Physician"
}

In the above-mentioned article, ${ }^{1}$ the electronic version differs from the print version due to a typo in Table 2. The second footnote should read "aspartate aminotransferase" instead of "aspartame aminotransferase." The electronic version on the Journal of the American Board of Family Medicine website has been corrected. We apologize for the error, and we regret any confusion or inconvenience it may have caused.

doi: $10.3122 /$ jabfm.2016.01.150354

\section{Reference}

1. Mookadam M, Shamoun FE, Mookadam F. Novel anticoagulants in atrial fibrillation: a primer for the primary physician. J Am Board Fam Med 2015;28: 510-22. 